\title{
Study on the Effect of Spatial Cognition Methods on Indoor Emergency Evacuation
}

\section{JINGJING XIONG}

Sichuan Normal University

YAN MAO ( $\sim$ maoyy85@163.com )

Sichuan Normal University

XUAN WANG

Sichuan Normal University

WU HE

Sichuan Normal University

\section{Research Article}

Keywords: way-finding capabilities, VR technology, YAH navigation maps

Posted Date: October 1st, 2021

DOl: https://doi.org/10.21203/rs.3.rs-922978/v1

License: (c) (1) This work is licensed under a Creative Commons Attribution 4.0 International License. Read Full License 


\section{Abstract}

In building fire emergencies,way-finding capabilities can affect people's evacuation efficiency and chances of survival.The purpose of this paper is to explore the influence of spatial cognitive methods on people's way-finding ability.In this research, we used VR technology to conduct experiments. In an immersive virtual environment,64 participants were asked to actively explore virtual malls by using YAH navigation and paper maps to find destinations and complete buying tasks,respectively.After that,32 participants needed to alienate the virtual mall with a time limit,while the else had to complete the same task without a time limit. In the experiment,the participants were exposed to the environment for the first time and were unfamiliar with it.The results showed that participants using paper maps walked longer(710 m vs $932 \mathrm{~m}$ ) and took more time(666 s vs $922 \mathrm{~s}$ ) to complete tasks of evacuating the mall than those who used YAH navigation maps. The findings also showed that participants spent more time(521 s vs 790 s)looking for exits under time constraints and found evacuation tasks more difficult.This article discusses the mechanisms of these findings.

\section{Introduction}

Fire is a serious disaster in interior buildings.According to the data of the National Fire Authority, in the first quarter of 2021 , a total of 389.77 people died due to building fires (https://www.119.gov.cn/article/3xBeBylHerh).In an indoor fire,the efficiency of evacuation and the chances of survival are greatly affected by the way-finding ${ }^{66}$. Way-finding is a process of people looking for a destination along path ${ }^{28}$.In essence,it is an action of cognition and problem solving,which consists of cognitive processes such as reading a map,remembering the route,_finding the position and maintaining the direction through external features or landmarks ${ }^{9-18}$.

Self-orientation and spatial orientation are two key processes in way-finding. However,with the development of the commercial economy,the tendency to be complicated of the internal structure of buildings not only increases the cognitive burden but also makes it difficult for people to find their way ${ }^{2}$.People's spatial knowledge of an unfamiliar environment of buildings comes from their cognition of spatial information such as landmarks,routes, and the whole in the environment 49 . Spatial knowledge is stored in people's mental representation of space,known as cognitive maps ${ }^{23}$.In the process of wayfinding,people extract spatial knowledge through cognitive maps ${ }^{19}$ and formulate reasonable way-finding strategies to guide way-finding behaviors ${ }^{50-51}$. The ability to find ways depends on people's use of route knowledge or overall knowledge ${ }^{2}$.

Maps are a major tool for people to obtain spatial information in an unfamiliar built environment ${ }^{42}$, which is beneficial for people to form cognitive maps covering the overall spatial information ${ }^{5}$.In the process of map navigation,people can obtain spatial geographic information about the entire environment from the map and carry out self-positioning and spatial orientation by combining the mapping between the text interface and environmental graphics ${ }^{65}$.Although paper maps can provide participants with complete 
spatial geographic information,they also increase the cognitive burden of users, who need to quickly identify spatial information,plan the path and reach the destination within a limited time ${ }^{48}$.

With the development of modern technology,a large amount of spatial geographic information is transmitted electronically through mobile phones and the Internet ${ }^{7505}$.People who_can place themselves in the physical space and space are shown in the map symbol matching, real-time position their position in space ${ }^{30168}$, and obtain more spatial information in a short time ${ }^{78,4}$ for spatial orientation and routes finding ${ }^{11,32}$.Compared with traditional paper maps,electronic maps have the advantage of quantitative judgment and can better communicate landmarks and route knowledge to users. However,some researchers have proposed that the use of electronic navigation is not good for people to acquire spatial knowledge about the environment ${ }^{24 \llbracket 25 \square 42}$..Moreover,compared with more traditional way-finding methods such as paper maps, technology-assisted way-finding will hinder people's acquisition of spatial knowledge ${ }^{18 \square 41042 \square 44 \llbracket 46}$.

Because of its real-time and interactive characteristics,electronic maps have been widely used in life However,as a carrier of information describing human life,paper maps still plan an important role in people's way-finding process,which is the priority for people to find their way ${ }^{22}$. Therefore,it is necessary to compare paper maps and electronic maps in modern society. Previous studies on paper maps and electronic maps mainly focus on outdoor way-finding and exploratory research ${ }^{5,6}$.For example,research on the application of paper maps in modern digital mapping society ${ }^{22}$;research on indoor navigation using augmented reality ${ }^{4}$ etc., while there are few studies on people using maps for indoor wayfinding.Second,in previous studies,paper maps and various electronic maps are mainly used in wayfinding behavior under normal circumstances, such as different studies of augmented reality (AR) and binary navigation electronic maps in people's way-finding behavior ${ }^{15}$. The influence of different information formats and spatial cognition on individual way-finding performance ${ }^{2}$. There is a lack of research on the design of indoor navigation interfaces compatible with human information processing in emergency situations,such as emergency evacuation ${ }^{61}$.Finally, when people are under great psychological pressure, which type of map is more efficient for evacuation is also a question worth exploring.

To understand indoor way-finding behavior efficiently and accurately, researchers have used various methods, such as questionnaires ${ }^{12}$,posture estimation ${ }^{60}$, and real-time tracking methods ${ }^{29}$. However,these experimental methods have some limitations.First,they lack overall experience with the environment.Second,they are expensive.Three, it is difficult for people to collect data and set up a controlled experimental environment.In recent years,virtual reality(VR) has been widely used in the research of human navigation and way-finding behavior ${ }^{6030.70}$ and is a "real or simulated environment that the perceive experiences remotely" ${ }^{53}$.VR (virtual reality) can provide a highly realistic virtual environment (IVE) to evoke participants' psychological and behavioral responses to a simulated environment with high ecological validity ${ }^{30 \square 61}$.The immersive virtual environment (IVE),as a new 
experimental method,provides a feasible alternative for indoor way-finding behavior research.Using an IVE-based approach,our goal is to examine two questions:

First,how do different ways of spatial cognition in indoor environments affect people's ability to find exist?

Second,how does stress in fire evacuation interact with spatial cognitive patterns to affect people's ability to escape fire emergencies?

\section{Methods}

\section{Participants}

In total,64 participants with normal vision or correction,no color blindness or other eye diseases were included in our research,and 32 participants were men;the other participants were women. They were randomly divided into 4 groups of 16 people,equally male and female.The experimental groups as shown in Table 2.The participants in the included articles had a mean age of 22-23 years and an equal percentage of men and women.Each participant received $50 \mathrm{CNY}$ for their participation. The participants were informed that they could quit the experiment at any time and were asked to sign an informed consent form before the experiment began. The study was approved by the Ethics Committee of Sichuan Normal University and all experimental procedures were performed in accordance with the Declaration of Helsinki.

\section{Experimental equipment}

To compare the different influences of modern navigation systems and traditional paper maps on emergency evacuation behavior in indoor fires,we selected one of the common navigation methods in VR,the YAH navigation map,which can be marked in real time for participant spatial locations that can be experimented with,and a traditional paper map to experiment.

\section{Experimental environment scenario}

In April 2021,a major fire in a commercial square in Anhui Province resulted in four deaths. In this experiment,we selected it as the script and took a medium-sized shopping mall as the experimental scene.Before the fire in the mall,the milk tea shop is launching a new ice cream. To eat the ice cream,everyone crowded in front of the milk tea shop to wait.In the experiment,all participants needed to arrive from the same mall entrance to buy ice cream at the milk cream store selling ice cream.

\section{Experimental scene}

The IVE used in this study is the first floor of a large virtual shopping mall,50 meters long, 40 meters wide,and 4 meters high.As seen in Fig. 1,there are 15 east-west stores in the mall,and a comprehensive 
mall is distributed in the center of the mall,including jewelry,clothing and other shops.Milk tea shop,route,and fire point have been replaced by small red flag,color line,and five-pointed star,respectively.

The mall has designed 4 conventional entrances and exits and five evacuation routes,as shown in Fig. 2.Furthermore,the participants did not walk through the walls across the IVE.As shown in a pentagram symbol in Fig. 1,there is 1 fire site for emergency fire experiment conditions. Flames at the fire point can spread to $3 \mathrm{~m} * 4 \mathrm{~m}$ and smoke to a considerable area to ensure that they can be seen anywhere in the mall (Fig. 3).

\section{Experimental design}

In this experiment,participants were divided into four groups,two of which needed to experiment by using paper maps,while the other two groups were required under the guidance of the YAH navigation map.In the experiment, the participants needed to complete the buying and evacuation tasks.As shown in Table 2.

During the buying task,participants in the paper map and YAH navigation map groups needed to arrive at the milk tea shop at normal walking speed $(1.2 \mathrm{~m} / \mathrm{s})$ to buy ice cream.Participants in the YAH navigation map group needed to set 5 coupons in the designated shop in turn using the following routes:from the entrance,successively through the bookstore,dining area, lounge,department store area,and clothing store to the makeup shop.After the participants arrived at the milk tea shop,fires suddenly occurred,and the participants were required to perform the evacuation task and leave the mall as soon as possible.For evacuation tasks,we used the design between participants in 2 (spatial cognition mode:paper maps and YAH navigation maps) 2 (experimental condition:time limit and no time limit).Before the experiment,the experimenter needed to calculate the average time when the participants of the paper and YAH navigation map groups evacuated without the evacuation time limit(according to previous studies,we assumed that the evacuation time obeys the normal distribution) and calculate the limited evacuation time (the mean reduces a standard difference) as the time limit condition of the experiment.Participants in the other two papers and YAH navigation maps were evacuated under experimental time constraints.

The entire experiment lasted approximately 4 mintes- 5 mintes to ensure that the participants could complete the experimental task.During the experiment,the participants used their own navigation aids to find the way,and they all participated for the first time and were unfamiliar with the experimental scene. The five evacuation routes designed in the experiment are as follows:route 1 is 40 m;route 2 is 30 $\mathrm{m}$,which is the shortest evacuation route;route 3 is $60 \mathrm{~m}$,which is the longest evacuation route;route 4 is 42 m;and route 5 is 50 m.As seen in Fig. 2.

\section{Experimental procedure}

The main experimental procedure of this study are summarized in Table 1.Participants arrive at the laboratory to sign the consent form and fill in the basic personal information:age,gender,occupation and so on. Then,participants were required to fill in the PANAS mood scale,enter the corresponding room 
showing the simple virtual environment,be familiar with the use of navigation map,operate the lever and complete the relevant tasks in the virtual environment.

Then,the experiment officially began.In the first stage,the participants of the map group freely explored the mall and arrived at the milk tea store;the YAH map group visited the designated store under the guidance of navigation to accumulate the discount coupons in proper order.The differences between the paper map group and the YAH navigation map group participants are that the paper map group participants have greater degrees of freedom in the route decisions.

In the experiment,the experimenter needed to calculate the average time when the participants of the paper and YAH navigation map groups evacuated without the evacuation time limit and calculate the limited evacuation time as the time limit condition of the experiment.Then, participants in the other two teams of paper and YAH navigation maps were evacuated under experimental time constraints.Upon arriving at the milk tea shop,a sign saying "you've arrived at your destination,please leave the mall as soon as possible (within 33 seconds)" appeared in front of the participants.Both virtual flames and smoke occur simultaneously.

After the experiment,participants completed the PANAS mood scale again to test the participants' psychological stress before and after the trail,as shown in Table 1.Participants will then need to answer the following questions:

(1) Rating the use of maps and navigation;

(2) Scores the difficulty of way-finding and evacuation;

(3)Evaluates the vividness of virtual shopping malls.

\section{Data analysis}

\section{way-finding behavior analysis}

In this study,we collected six measurements to assess the performance,mainly their walking time,walking distance and route selection in the buying and evacuation tasks. The main findings of these data are summarized in the following Tables 3,4,5,6,7,8:

First,we analyzed the walking time and walking distance of buying tasks 2 (spatial cognitive method: paper map group or YAH navigation map group) and 2 (experimental conditions:time limit and no time limit) between the participants. The results showed that there were no significant differences in spatial cognitive patterns in terms of walking distance of the buying task: $(F(1,30)=0.009156, P=0.924404$, Fcrit $=4.170877$ ),as shown in Fig. 4.From the point of view of walking time,the difference of spatial cognition mode will not cause significant difference $(F(1,30)=3.050157, P=0.090963, F$ crit $=$ 4.170877. These results show that participants who use YAH navigation maps are not very different from 
those who use paper maps in the distance and time spent buying tasks. The difference between sex and walking distance and time was also not significant $(P=0.5>0.05 ; P=0.509017>0.05)$.

At the same time,the variance analysis of 2 (spatial cognition: paper map group or YAH navigation map group) 2 (experimental conditions:time limit and no time limit) shows that different spatial cognitive patterns have a significant effect on the distance of evacuation: $(F(1,30)=6.595162, p=0.015448, F$ crit $=4.170877$ ), and the differences in spatial cognition can also have a significant impact on the time of evacuation in terms of evacuation time $(F(1,30)=7.52434, p=0.01017, F$ crit=4.170877), as shown in Fig. 5.These results show that participants who used paper maps traveled longer distances ( $710 \mathrm{~m}$ vs $932 \mathrm{~m}$ ) and took more time (666 s vs $922 \mathrm{~s}$ ) than participants who used YAH navigation maps,as shown in Fig. 4. The difference between sex and evacuation distance and time was not significant $(P=0.52314>0.05 ; P=$ $0.382004>0.05)$.

Finally,the experimental results also show that there is no interaction between gender and spatial cognition;that is,there is no interaction between gender and spatial cognition on the walking time and distance of snatching and evacuation tasks.

We also performed an ANOVA with 2 (spatial cognition mode: paper map or YAH navigation map) * 2 (experimental conditions:time limit and no time limit) * 2 (evacuation behavior:time or distance). We investigated whether different spatial cognitive approaches and experimental conditions interacted with evacuation time. The results showed that different spatial cognition and experimental conditions interact with evacuation time and under evacuation time limit,in contrast to the participants in the YAH navigation map,participants using paper maps were evacuated at longer distances $(F(1,30)=13.66, p=0.00087$, Fcrit=4.1701),(523 m vs $727 \mathrm{~m})$, and more time $(F(1,30)=12.067, p=0.00158$, Fcrit=4.171), (521 s vs790 s), as shown in Fig. 5.

To test for differences in sex in experiments,we performed ANO variance on 2 (spatial cognitive mode:paper or YAH navigation maps) * 2 (experimental conditions:time limit and no time limit) * 2 (gender:male or female).Experimental results showed that neither the main effect of sex nor the interaction effect between sex and other independent variables were significant.

\section{Results}

The focus of this experimental study is the spatial cognitive efficiency of participants under different spatial cognitive modalities and therefore a comparative analysis between spatial cognitive efficiencies under different spatial cognitive modalities.Participants shared spatial cognition in two categories (paper maps and YAH navigation maps).First,in the analysis of path selection for participants,as shown in Fig. 6 below,path selection varies greatly between groups and spatial cognitive methods,and path selection varies significantly.In normal evacuation tasks, 4 participants $(25 \%)$ chose the shortest path 2 using the paper map,while 8 participants (50\%) chose path 2 using the YAH navigation map. With the evacuation time limit,3 participants(19\%) using the paper map selected the shortest path 2,while 12 participants(75\%) using the YAH navigation map selected path 2, as shown in Fig. 6 : 
In the experimental scenario of this paper,we designed the shortest path,route 2 .We analyzed in our experiments that the percentage of participants using the YAH navigation maps who correctly selected the shortest route was $63 \%$ compared to participants using paper maps. Experimental results showed that participants using YAH navigation maps had more spatial cognition than those using paper maps,namely,that YAH navigation maps were more favorable to participants' access to spatial knowledge.

\section{Subjective evacuation and analysis}

We summarized all the subjective evaluations of the participants.First,we performed a mixed design ANOVA of 2 (experimental stage: before or after experiment) * 2 (experimental conditions: time limit and no time limit), which was an internal factor and experimental condition between subjects. The results showed significant differences in fear ratings before and after the experiment.Participants with the evacuation time limit felt more afraid after the experiment than before the experiment,while participants without the evacuation time limit group did not differ greatly in mood changes before and after the experiment.These results suggest that participants did change in psychological pressure with evacuation time limits compared to the no time limit group.We also performed a mixed design ANOVA of 2 (experimental conditions:time limit and no time limit)*2(gender:male or female).Experimental results showed that female participants were more prone to changes in psychological stress than male participants.

Based on this basis,we also estimated an ANOVA of the difficulty of buying task and evacuation task 2 (spatial cognitive mode:paper or YAH navigation map group) *2 (experimental condition: time limit and no time limit), which showed that different spatial cognitive methods significantly affected the difficulty,which participants using paper maps considered harder to complete than participants using the YAH navigation map.The results also showed that for the difficulty evaluation of the evacuation task,the difference in experimental conditions had significant effects and that participants with an evacuation time limit than no evacuation time limit participants considered a successful evacuation task harder.No other major or interaction effects were significant.

Finally, this paper was also tested for independence for each of the following confounders, including the degree of participants' familiarity with the VR environment and the vividness of the virtual environment.

\section{Discussion}

The main findings and effects of this study are summarized in Table 9.This section discusses these findings in further detail.

\section{Effect of different spatial cognition methods on evacuation behavior.}

In conclusion, the results of this study show that the participants of paper map groups walk for a long distance and time during buying tasks.YAH navigation maps can save subject cognitive 
resources ${ }^{64}$.Participants using paper maps require intensive,complex spatial knowledge acquisition and processing processes. This is consistent with the conclusions of Kruger and Munzer,where mobile navigation techniques better communicate landmarks and routes to users for route finding compared to traditional maps.In addition,during the experiment,the YAH navigation map group tried to follow the planned route of navigation,so it was shorter than the average length of the route of the paper map group.This is demonstrated by a review of the experimental video,with a detour or return of $19 \%$ (6 of 32) in the paper maps,causing them to spend more time on the longer route completing the buying task.

The results also show that the paper map group participants walked longer in the evacuation task than the YAH navigation map group participants and considered the task more difficult.The main reason for this difference between the two groups of participants is as follows:first,the goal of the evacuation task.The goal in this study is to find the mall exit.In the evacuation task,the participants do not need a complete space cognitive map,and the space knowledge related to the exit location is sufficient to help participants find the exit of the mall.Cao Li jun and others also found that participants with some spatial knowledge tended to evacuate through the routes they were familiar with.Second,participants exploring the space along the route specified in the YAH navigation map do not need to compare the spatial representation on the map with the environment to find the specified location. They can follow the realtime guidance of the navigation map and maintain a relatively stable forward direction,the direction of the exit.Finally, in the experimental process,the paper map group participants may go in the wrong direction,circle or return behavior,causing confusion regarding spatial cognition.In summary,in the case of indoor fire bursts, the YAH navigation map is more conductive to guiding people's emergency evacuation behavior.

\section{Effect of the experimental conditions with evacuation restrictions on the evacuation behavior}

The results of this experiment also show that the participants spent more time searching out the mall exit and considered the evacuation task more difficult.These results are consistent with those of Cao Li jun (2019),etc.,where participants in fire emergency conditions escape longer than participants finding exits in normal conditions. These findings indicated that the evacuation time limits had important effects on the participants' evacuation performance during the evacuation task.First,the participants produced a stress psychological response to fire incidents and felt more scared after the experiment than before the experiment ${ }^{66,47}$.People in fire emergencies have greater physical and psychological stress,different perception patterns,different behavior patterns, and poor road-finding ability 45 .

Proulx's pressure model (1993) also shows that people will feel fear or stress in the face of a sudden fire.In this paper,we control people's psychological stress by controlling evacuation time and find that participants have greater psychological pressure in the time limit compared to participants in the no timelimited group.There was a significant increase in pressure in the time-limited compared to participants in the no time-limited group.A significant increase in pressure creates a high pressure stats that limits people's ability to deal with environmental information effectively ${ }^{45}$ and leads to a decrease in evacuation efficiency. 
Meanwhile, the results also showed that there was no significant difference in the walking distance of the successful evacuation. This suggests that although the presence of evacuation time limits can affect the subject's ability to perceive and process environmental information,these restrictions do not affect their ultimate success in finding the right route to the exit.

Finally,we find that the experimental conditions with evacuation time limit have no significant effect on the vividness of the virtual environment and the participants' familiarity with the virtual environment.Therefore, it can be shown that the differences in the trial times in this study were not caused by individual differences.

\section{Effect of different spatial cognition methods on the spatial cognition efficiency}

Participants in paper map groups varied significantly in the choice of paths. Using paper maps, 7 people selected path 2 (22\%);the YAH navigation map group subjects also differed significantly in path selection,with 20 people selected path $2(63 \%)$.In this paper,we control for factors such as gender,population density and spatial cognition within the two groups and consider only the different route selection between groups. Experimental results show that the YAH navigation maps choose the shortest route (22\% vs $63 \%$ ) compared with the participants in paper maps,namely, the YAH navigation map is more conducive to obtaining spatial knowledge about the environment and improving people's spatial cognitive efficiency of the environment.This is inconsistent with the results of Golledge and Aslan that technology-assisted routing reduces spatial knowledge gained compared to more traditional pathfinding methods such as using paper maps.

\section{Limitations}

There are some limitations in the study of this paper,which can be corrected in future research.First,the experiment only considered the impact of two spatial cognitive methods on people's ability to explore roads in fire.Due to the lack of research on other spatial cognitive methods,other spatial cognitive methods can be studied in the future.Second,the number of participants is limited,so the results are not very representative;expanding and including human age and expertise will be a good choice in the future.Finally,way-finding is a complex cognitive process, and each of these steps may be affected by spatial cognitive methods and fire emergencies. In the future,it will be possible to study the influence of dynamic changes in fire on way-finding behavior.

\section{Conclusion}

Our study demonstrated several conclusions.First,the YAH navigation map is more beneficial to guide the behavior of emergency evacuation.Second,the YAH navigation mapping group is more conducive to obtaining spatial knowledge about the environment and improving people's spatial cognition efficiency of the environment.Finally,psychological stress will limit people's ability to effectively process environmental information and reduce evacuation efficiency. 


\section{Declarations}

\section{Data availability}

The data and material of the current study will be available from the corresponding author upon reasonable request.

\section{References}

1. Allen, G. L et al. "Spatial Abilities,Cognitive Maps,and Way-finding:Bases for Individual Differences in Spatial Cognition and Behavior." way-finding behavior",46--80 (1999).

2. Antoine Verghote,Sara Al-Haddad,Paul Goodrum,Sylvie Van Emelen.The Effects of Information Format and Spatial Cognition on Individual Way-finding Performance. Buildings,9(2),29 (2019).

3. Antti Oulasvirta,Sara Estlander,Antti Nurminen.Embodied interaction with a 3D versus 2D mobile map. Personal and biquitous Computing,13(4),303-320(2009).

4. Ashly Martin et al.Indoor Navigation using Augmented Reality. EAl Endorsed Transactions on Creative Technologies,8(26), (2021).

5. Ben-Elia E.An exploratory real-world way-finding experiment:A comparison of drivers' spatial learning with a paper map vs.turn-by-turn audiovisual route guidance. Transportation Research Interdisciplinary Perspectives,9 (2021).

6. Bosco, A., Picucci, L., Caffò, A. O., Lancioni, G. E., \& Gyselinck, V. Assessing human reorientation ability inside virtual reality environments:The effects of retention interval and landmark characteristics. Cognitive Processing, 9(4),299-309(2008).

7. Brewer M B. Research design and issues of validity. Handbook of research methods in social and personality psychology3-16. 11-26(2000).

8. Bryan, JL. Human behavior in fire:The development and maturity of a scholarly study area._Fire and materials,23(6),249-253(1999).

9. Chen,JL et al.A theoretical model of way-finding in virtual environments:Proposed strategies for navigational aiding.Presence,8(6),671-685(1999).

10. Chrastil,Elizabeth et al.Active and Passive Spatial Learning in Human Navigation: Acquisition of Graph Knowledge. Journal of Experimental Psychology. Learning,Memory \& Cognition, 41(4),11621178 (2015).

11. Christian Kray,Christian Elting,Katri Laakso,Volker Coors.Presenting route instructions on mobile devices. Intelligent user interfaces,117-124(2003).

12. Christoph Hölscher,Simon J.Büchner,Tobias Meilinger,Gerhard Strube.Adaptivity of way-finding strategies in a multi-building ensemble:The effects of spatial structure,task requirements,and metric information. Journal of Environmental Psychology,29(2), 208-219(2008).

13. Delamater Andrew R. Inaugural editorial for Journal of Experimental Psychology:Animal Learning and Cognition. Journal of experimental psychology. Animal learning and cognition, 46(2), 99-100 
『2020》.

14. Dolins,Francine et al.Technology advancing the study of animal cognition:using virtual reality to present virtually simulated environments to investigate nonhuman primate spatial cognition._Current Zoology, 63(1),97-108(2017)

15. Dong Weihua et al.What is the difference between augmented reality and 2D navigation electronic maps in pedestrian way-finding? Cartography and Geographic Information Science,48(3),225240(2021).

16. G. Proulx.A stress model for people facing a fire.Journal of Environmental Psychology, 13(2),137147(1993).

17. GoebelR, et al.Learning, Reasoning, and Talking about Space. Berlin:Springer-Verlag:171-187.(2008).

18. Golledge, R.G.,Dougherty et al.Acquiring Spatial Knowledge:Survey Versus Route-Based Knowledge in Unfamiliar Environment. Annals of the Association of American Geographers 85(1),134158(1995).

19. He,Qiliang et al.Acquisition and Transfer of Spatial Knowledge During Way-finding.Journal of Experimental Psychology. Learning, Memory \& Cognition,45(8),1364-1386(2019).

20. Herganl et al. Comparison of children's way-finding,using paper map and mobile navigation. International research in geographical and environmental education,26(2),91-106(2017).

21. Hiromune Namie,Osamu Suzuki. Indoor Location Estimation by Bluetooth Low Energy for Pedestrian Navigation:Paper. IEEJ Journal of Industry Applications,10(1),45-52(2021).

22. Hurst,Paul et al.Will we be lost without paper maps in the digital age? Journal of Information Science, 39(1),48-60(2013).

23. Iaria Giuseppe,Slone Edward.The relationship between mental and physical space and its impact on topographical disorientation. Handbook of clinical neurology178,195-211(2021)

24. Ishikawa,T et al.Spatial knowledge acquisition from direct experience in the environment: Individual differences in the development of metric knowledge and the integration of separately learned places.Cognitive Psychology,52(2),93-129(2006).

25. Ishikawa,T.et al.Way-finding with a GPS-based mobile navigation system:A comparison with maps and direct experience. Journal of Environmental Psychology,28,74 - 82 (2008).

26. Jamshidi Saman,et al."A Narrative Review of Theories of Way-finding Within the Interior Environment." HERD:Health Environments Research \& Design Journal 14.1,290-303 (2021)

27. Jansen Osmann Petra,Schmid Juliane,Heil Martin.Way-finding behavior and spatial knowledge of adults and children in a virtual environment:The role of environmental structure. Swiss Journal of Psychology/Schweizerische Zeitschrift für Psychology/Reven_Suisse de Psychologie,66(1),4150(2007)

28. K. A.Jellinger.Way-finding Behavior,Cognitive Mapping and Other Spatial Processes Reginald G. Golledge,ed. The Johns Hopkins University Press, Baltimore \& London, 1999. ISBN 0-8010-5993-X. European Journal of Neurology,7(5),590-591 (2000). 
29. Kirsten M.Kinsley,Dan Schoonover,Jasmine Spitler.GoPro as an ethnographic tool:A way-finding study in an academic library. Journal of Access Services,13(1), 7-23(2016).

30. Lin, Jing et al.Do people follow the crowd in building emergency evacuation?A cross-cultural immersive virtual reality-based study.Advanced Engineering Informatics,43,2020.

31. Lloyd,R Bunch et al.Technology and map-learning:Users,methods, and symbols. Annals of the Association of American Geographers,93(4),828-850(2003).

32. Lokka,Ismini et al.Perspective switch and spatial knowledge acquisition:effects of age, mental rotation ability and vision spatial memory capacity on route learning in virtual environments with different levels of realism. Cartography and Geographic Information Science, 47(1),14-27(2020).

33. Lovreglio,Ruggiero et al.Prototyping virtual reality serious games for building earthquake prepae goiredness:The Auckland City Hospital case study.Advanced Engineering Informatics, 38,670682(2018).

34. Mallory C.et al.Where are we and where have we been?Examining the effects of maps on spatial learning in an indoor guided navigation task. Cognitive Research: Principles and Implications,5(3),7386 (2020).

35. Manning,J.R. et al.Magellan:A cognitive map-based model of human way-finding. Journal of experimental psychology. General, 143(3),1314-1330(2014).

36. Mark D M et al.Cognitive Models of Geographical Space.INT. J.Geographical Information Science,13 08,747-774(1999).

37. Meng,Fanxing et al.Way-finding during a fire emergency:an experimental study in a virtual environment.Ergonomics,57(6),816-827(2014).

38. Montello D R.D Waller,Hegarty M,et al.Spatial memory of real environments,virtual environments, and maps. Atherosclerosis,41(2-3),185-192(2004).

39. Montello D R.Raubal M.Waller D.et al.Functions and applications of spatial cognition. Handbook of Spatial Cognition,249-264₫2013区.

40. Montello,Daniel et al.Cognitive map-design research in the twentieth century:Theoretical and

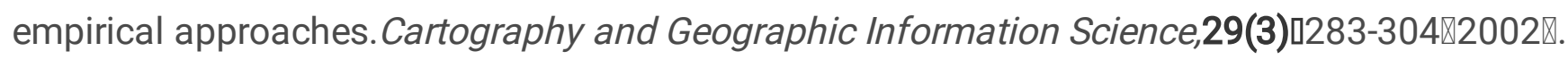

41. Münzer Stefan,Lörch Lucas,Frankenstein Julia.Way-finding and acquisition of spatial knowledge with navigation assistance. Journal of experimental psychology.Applied,26(1), 73-88(2020).

42. Münzer,S.Zimmer et al.Computer-assisted navigation and the acquisition of route and survey knowledge. Journal of Environmental Psychology,26(4),300-308(2006).

43. Münzer,S. Zimmer et al.Navigation assistance:A trade-off between way-finding support and configure learning support.Journal of experimental psychology.Applied, 18(1),18-37(2012).

44. Münzer,S.,Zimmer et al.Computer-assisted navigation and the acquisition of route and survey knowledge. Journal of Environmental Psychology, 26(4),300-308(2006).

45. Ozel,F.Time pressure and stress as a factor during emergency egress. Safety Science,38(2),95107(2001). 
46. Parush,A.,Ahuvia,S.,Erev,I.,Degradation in spatial knowledge acquisition when using automatic navigation systems. Spatial Inf. Theory, 238-254(2007).

47. Proulx,G. A. stress model for people facing a fire. Journal of Environmental Psychology, 13(2),137147(1993).

48. Shi,Yangming et al.Spatial knowledge and firefighters' way-finding performance:A virtual reality search and rescue experiment. Safety Science,139(2021).

49. Siegel,A. W.,\&White,S.H.The development of spatial representations of large-scale environments.Advances in Child Development and Behavior,10, 9- 55(1975).

50. Spiers $\mathrm{H}$ J,Maguire $E \mathrm{~A}$. The dynamic nature of cognition during way-finding. Journal of Environmental Psychology,28(3),232-249(2008)

51. Spiers,H.J.,Maguire, E.A.Thoughts,behaviour,and brain dynamics during navigation in the real world.Neurolmag 31,1826-1840(2006).

52. Steinke T R.Eye movement studies in cartography and related fields. Cartographical, 24(2),197221(1987).

53. Steuer,J.Defining Virtual Reality:Dimensions Determining Telepresence. Journal of Communication,42(4),73-93(1992).

54. Tejera,Gonzalo et al.Bio-Inspired Robotics:A Spatial Cognition Model integrating Place Cells,Grid Cells and Head Direction Cells. Journal of intelligent \& robotic systems,91(1),85-99(2018).

55. van,der,Kuil et al.Spatial knowledge acquired from first-person and dynamic map perspectives. Psychological research, 85(6),2137-2150(2020).

56. Wang Duming et al.A comparative study of spatial orientation performance of YAH map in different display modes. Human ergonomics,16(4),1-6. (2010).

57. Wang,Zhuo et al.The role of user-centered AR instruction in improving novice spatial cognition in a high-precision procedural task.Advanced Engineering Informatics,47(2021).

58. Wu Zenghong,Chen Weifen.New products in map science and the transformation of human spatial cognitive ability. Beijing surveying and mapping, (04),11-14(2008).

59. Xiong,Qing et al.A Dynamic Indoor Field Model for Emergency Evacuation Simulation. ISPRS International Journal of Geo-Information, 6(4),104(2017).

60. Zhao, Haifeng et al.A Time-Aware Routing Map for Indoor Evacuation. Sensors, 16(1),112(2016).

61. Zheng Meng-Cong et al.Designing indoor navigation interfaces on smartphones compatible with human information processing in an emergency evacuation scenario. Journal of Asian architecture and building engineering,18(6),599-616(2019).

62. Zou,Hao et al.Emotional Response-Based Approach for Assessing the Sense of Presence of Subjects in Virtual Building Evacuation Studies. Journal of Computing in Civil Engineering, 31(5),4017028.14017028.1(2017).

63. Bouchekioua,Youcef et al.Spatial inference without a cognitive map:the role of higher-order path integration. Biological reviews of the Cambridge Philosophical Society, 96(1),52-65(2021). 
64. Jing Lin,Lijun Cao,Nan Li. Assessing the influence of repeated exposures and mental stress on human way-finding performance in indoor environments using virtual reality technology. Advanced Engineering Informatics,39, 53-61(2019).

65. Li et al."How the completeness of spatial knowledge influences the evacuation behavior of passengers in metro stations:A VR-based experimental study".Automation in Construction,113(2020).

66. Lijun Cao,Jing Lin,Nan Li. A virtual reality based study of indoor fire evacuation after active or passive spatial exploration. Computers in Human Behavior,90, 37-45(2019).

67. Montello,D. Spatial cognition.Int.Encyclo.Soc.Behav. Sci.7,14771-14775(2001).

68. Meilinger T.et al.How Much Information Do You Need Schematic Map sin Way-finding and Self Localization[M]// Barkowsky T,Knauff M. Spatial Cognition V.Reasoning,Action, Interaction.Berlin:Springer-Verlag,381-400(2006).

69. Van,Asselen,M.et al.The influence of intentional and incidental learning on acquiring spatial knowledge during navigation. Psychological research,70(2),151-156(2006).

70. Zhu,Runhe et al.Influence of architectural visual access on emergency way-finding:A cross-cultural study in China,United Kingdom and United States.Fire safety journal,113(,2020).

\section{Tables}

Table 1 Experimental procedure
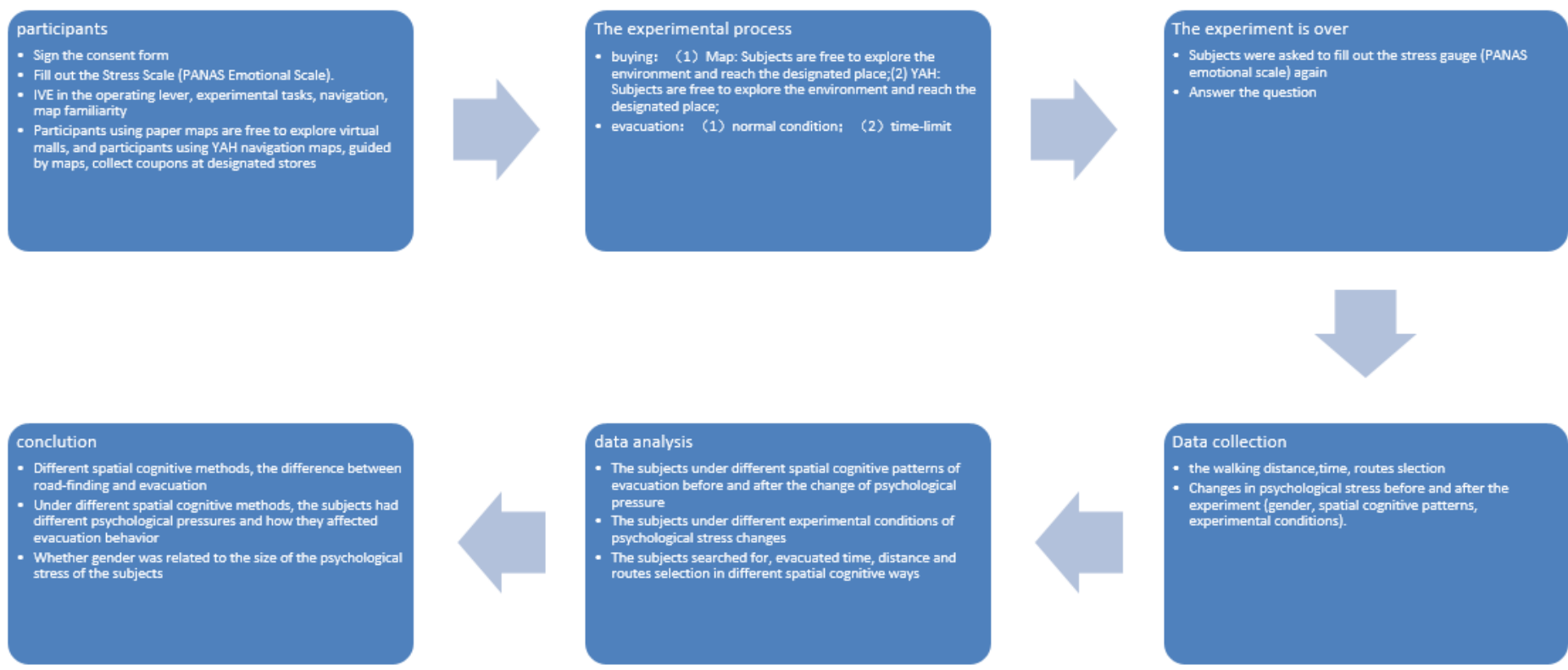

Table 2 The Experimental groups 


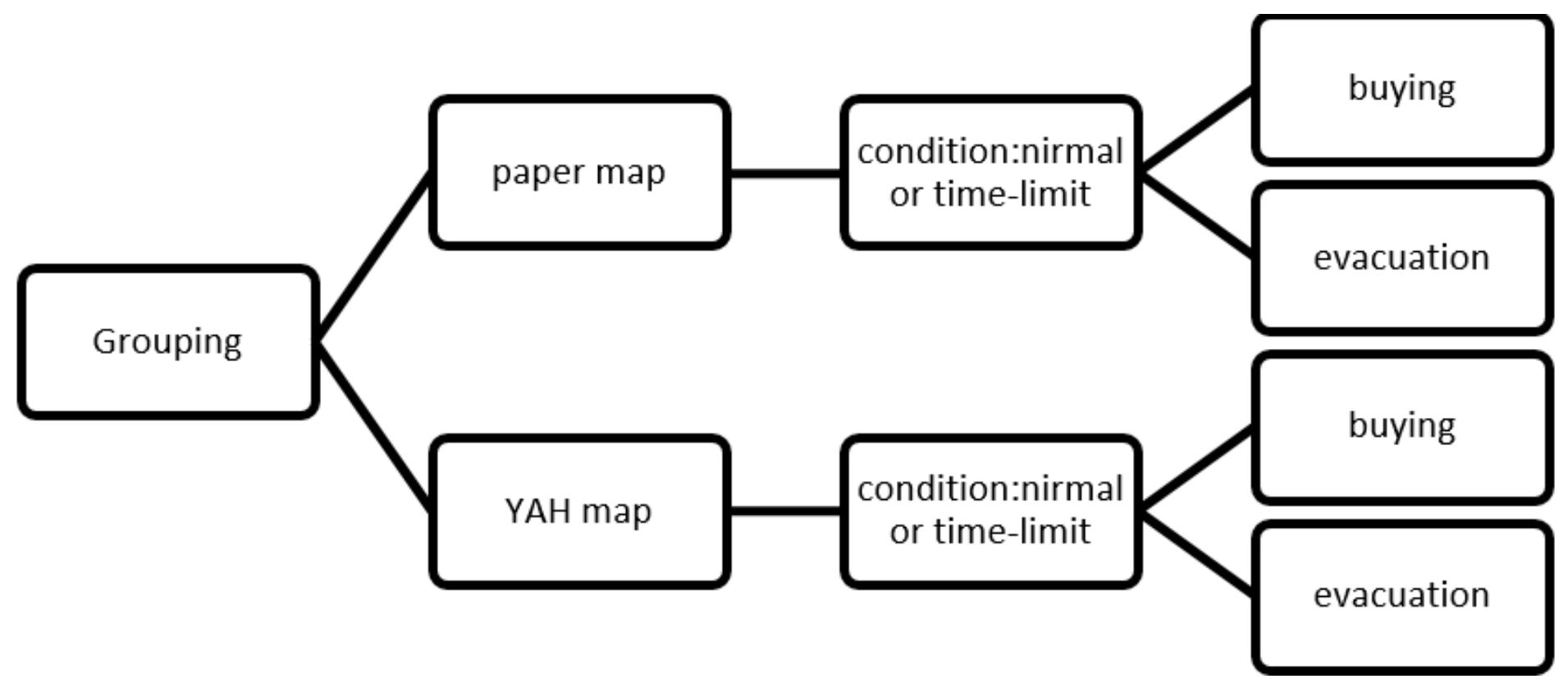

Table 3

The waking distance of different spatial

cognition methods under normal condition

\begin{tabular}{|llll|}
\hline $\begin{array}{l}\text { Paper Map } \\
\text { (Buying) }\end{array}$ & $\begin{array}{l}\text { YAH } \\
\text { (Buying) }\end{array}$ & $\begin{array}{l}\text { Paper map } \\
\text { (Evacuation) }\end{array}$ & $\begin{array}{l}\text { YAH } \\
\text { (Evacuation) }\end{array}$ \\
\hline 141 & 110 & 101 & 61 \\
\hline 130 & 100 & 87 & 57 \\
\hline 124 & 99 & 78 & 50 \\
\hline 118 & 98 & 70 & 49 \\
\hline 112 & 97 & 67 & 49 \\
\hline 99 & 93 & 62 & 48 \\
\hline 96 & 92 & 59 & 46 \\
\hline 89 & 92 & 54 & 43 \\
\hline 78 & 91 & 52 & 43 \\
\hline 76 & 91 & 52 & 42 \\
\hline 73 & 89 & 49 & 41 \\
\hline 72 & 89 & 47 & 40 \\
\hline 70 & 88 & 39 & 38 \\
\hline 69 & 87 & 36 & 36 \\
\hline 69 & 79 & 35 & 36 \\
\hline 68 & 79 & 35 & \\
\hline
\end{tabular}


Table 4

The waking time of different spatial cognition methods under normal condition

\begin{tabular}{|llll|}
\hline $\begin{array}{l}\text { Paper map } \\
\text { (Buying) }\end{array}$ & $\begin{array}{l}\text { YAH } \\
\text { (Buying) }\end{array}$ & $\begin{array}{l}\text { Paper map } \\
\text { (Evacuation) }\end{array}$ & $\begin{array}{l}\text { YAH } \\
\text { (Evacuation) }\end{array}$ \\
\hline 260 & 160 & 97 & 70 \\
\hline 217 & 152 & 89 & 50 \\
\hline 203 & 130 & 89 & 49 \\
\hline 169 & 126 & 75 & 46 \\
\hline 161 & 121 & 68 & 46 \\
\hline 159 & 121 & 61 & 43 \\
\hline 150 & 119 & 60 & 43 \\
\hline 148 & 118 & 53 & 42 \\
\hline 134 & 117 & 51 & 39 \\
\hline 108 & 116 & 51 & 39 \\
\hline 101 & 115 & 51 & 38 \\
\hline 97 & 110 & 40 & 38 \\
\hline 95 & 110 & 39 & 36 \\
\hline 95 & 101 & 36 & 29 \\
\hline 92 & 98 & 32 & 30 \\
\hline 88 & 81 & & 29 \\
\hline
\end{tabular}


Table 5

The waking distance of different spatial cognition methods under time-limit

\begin{tabular}{|llll|}
\hline Paper map(Buying) & $\begin{array}{l}\text { YAH } \\
\text { (Buying) }\end{array}$ & Paper map(Evacuation) & YAH(Evacuation) \\
\hline 99 & 91 & 50 & 29 \\
\hline 101 & 87 & 72 & 31 \\
\hline 97 & 92 & 34 & 28 \\
\hline 78 & 89 & 32 & 27 \\
\hline 74 & 88 & 42 & 30 \\
\hline 67 & 89 & 62 & 29 \\
\hline 109 & 93 & 42 & 39 \\
\hline 132 & 87 & 41 & 32 \\
\hline 79 & 86 & 42 & 26 \\
\hline 116 & 85 & 51 & 41 \\
\hline 132 & 86 & 52 & 27 \\
\hline 95 & 90 & 31 & 28 \\
\hline 87 & 91 & 61 & 42 \\
\hline 124 & 88 & 41 & 30 \\
\hline 96 & 87 & 43 & 51 \\
\hline 89 & 31 & & 33 \\
\hline
\end{tabular}


Table 6

The waking time of different spatial cognition

methods under time-limit

\begin{tabular}{|llll|}
\hline $\begin{array}{l}\text { Paper map } \\
\text { (Buying) }\end{array}$ & $\begin{array}{l}\text { YAH } \\
\text { (Buying) }\end{array}$ & $\begin{array}{l}\text { Paper map } \\
\text { (Evacuation) }\end{array}$ & $\begin{array}{l}\text { YAH } \\
\text { (Evacuation) }\end{array}$ \\
\hline 178 & 108 & 41 & 30 \\
\hline 210 & 110 & 92 & 26 \\
\hline 143 & 101 & 38 & 24 \\
\hline 121 & 99 & 40 & 22 \\
\hline 101 & 103 & 49 & 26 \\
\hline 97 & 110 & 71 & 30 \\
\hline 189 & 116 & 39 & 41 \\
\hline 201 & 102 & 43 & 27 \\
\hline 110 & 94 & 41 & 21 \\
\hline 154 & 104 & 60 & 40 \\
\hline 178 & 99 & 61 & 31 \\
\hline 118 & 131 & 35 & 27 \\
\hline 108 & 101 & 56 & 50 \\
\hline 189 & 134 & 39 & 29 \\
\hline 103 & 109 & 45 & 67 \\
\hline 99 & 107 & 40 & 30 \\
\hline
\end{tabular}

Table 7

The waking time and distance of different spatial cognition methods under normal condition

\begin{tabular}{|llll|}
\hline YAH & Sum & Average & Standard deviation \\
\hline Buying distance & 1474 & 92.125 & 16.13225 \\
\hline Buying time & 1895 & 118.4375 & 32.69395 \\
\hline Evacuation distance & 710 & 44.375 & 13.27849 \\
\hline Evacuation time & 666 & 41.625 & 16.22417 \\
\hline Paper map & Sum & Average & Standard deviation \\
\hline Buying distance & 1484 & 92.75 & 18.308 \\
\hline Buying time & 2277 & 142.3125 & 39.53689 \\
\hline Evacuation distance & 932 & 57.6875 & 15.76153 \\
\hline Evacuation time & 922 & 57.625 & 18.05029 \\
\hline
\end{tabular}


Table 8

The waking time and distance of different spatial cognition methods under time-limit condition

\begin{tabular}{|llll|}
\hline YAH map & Sum & Average & Standard deviation \\
\hline Buying distance & 1415 & 88.44 & 2.39 \\
\hline Buying time & 1728 & 108 & 10.99 \\
\hline Evacuation distance & 523 & 32.69 & \multicolumn{2}{l}{6.97} \\
\hline Evacuation time & 521 & 32.56 & 11.88 \\
\hline Paper map & Sum & Average & Standard deviation \\
\hline Buying distance & 1575 & 98.44 & 28.84 \\
\hline Buying time & 2299 & 143.69 & 41.22 \\
\hline Evacuation distance & 727 & 45.44 & 11.91 \\
\hline Evacuation time & 790 & 49.38 & 15.28 \\
\hline
\end{tabular}

Table 9 The main findings and effects of this study

\begin{tabular}{|c|c|c|}
\hline Independent variable & Dependent variable & result \\
\hline \multirow[t]{8}{*}{ Spatial cognition: A paper map or YAH navigation map } & The walking time of the buying task & $\begin{array}{l}\text { No significant } \\
\text { difference }\end{array}$ \\
\hline & The walking distance of the buying task & $\begin{array}{l}\text { No significant } \\
\text { difference }\end{array}$ \\
\hline & $\begin{array}{l}\text { Assessment of the difficulty of buying } \\
\text { tasks }\end{array}$ & $\begin{array}{l}\text { Paper map > YAH } \\
\text { map }\end{array}$ \\
\hline & $\begin{array}{l}\text { Evaluation of the difficulty of using paper } \\
\text { maps }\end{array}$ & $\begin{array}{l}\text { Paper map > YAH } \\
\text { map }\end{array}$ \\
\hline & $\begin{array}{l}\text { YAH navigation maps use difficulty } \\
\text { assessments }\end{array}$ & $\begin{array}{l}\text { Paper map > YAH } \\
\text { map }\end{array}$ \\
\hline & $\begin{array}{l}\text { Percentage of shortest path selection for } \\
\text { paper maps }\end{array}$ & $22 \%$ \\
\hline & $\begin{array}{l}\text { Percentage of shortest path selection for } \\
\text { YAH maps }\end{array}$ & $63 \%$ \\
\hline & $\begin{array}{l}\text { The walking distance of the evacuation } \\
\text { task }\end{array}$ & $\begin{array}{l}\text { Paper map > YAH } \\
\text { map }\end{array}$ \\
\hline \multirow{2}{*}{$\begin{array}{l}\text { Experimental conditions: No evacuation time limit or } \\
\text { evacuation time limit }\end{array}$} & The walking time of the evacuation task & normal > time-limit \\
\hline & The difficulty of the evacuation task & time-limit $>$ normal \\
\hline \multirow[t]{2}{*}{ Experimental stage: Before or after an experiment } & Nervousness & Before $>$ after \\
\hline & fear & Before $>$ after \\
\hline
\end{tabular}

\section{Figures}




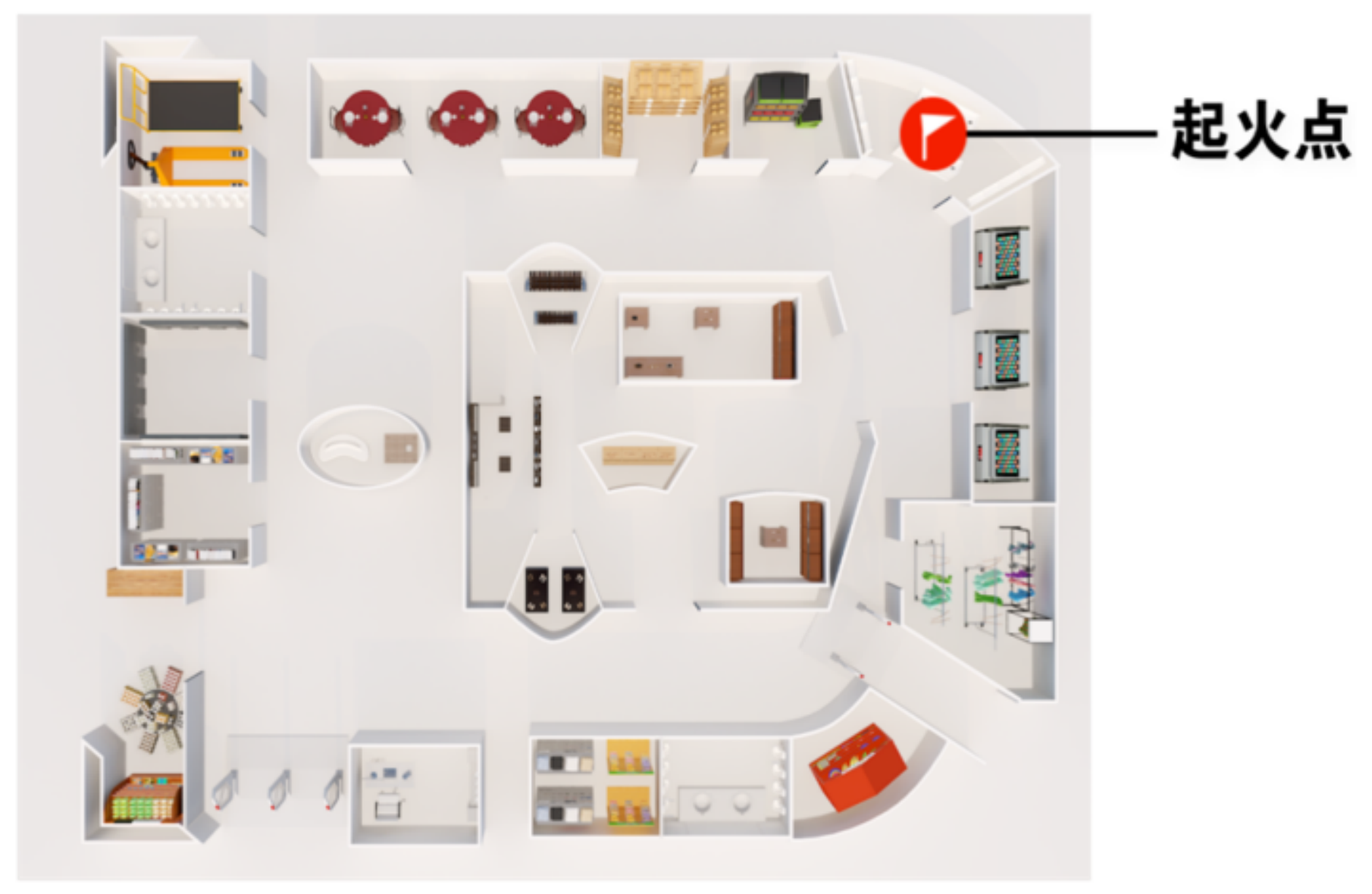

Figure 1

Illustration of the structure of the mall 


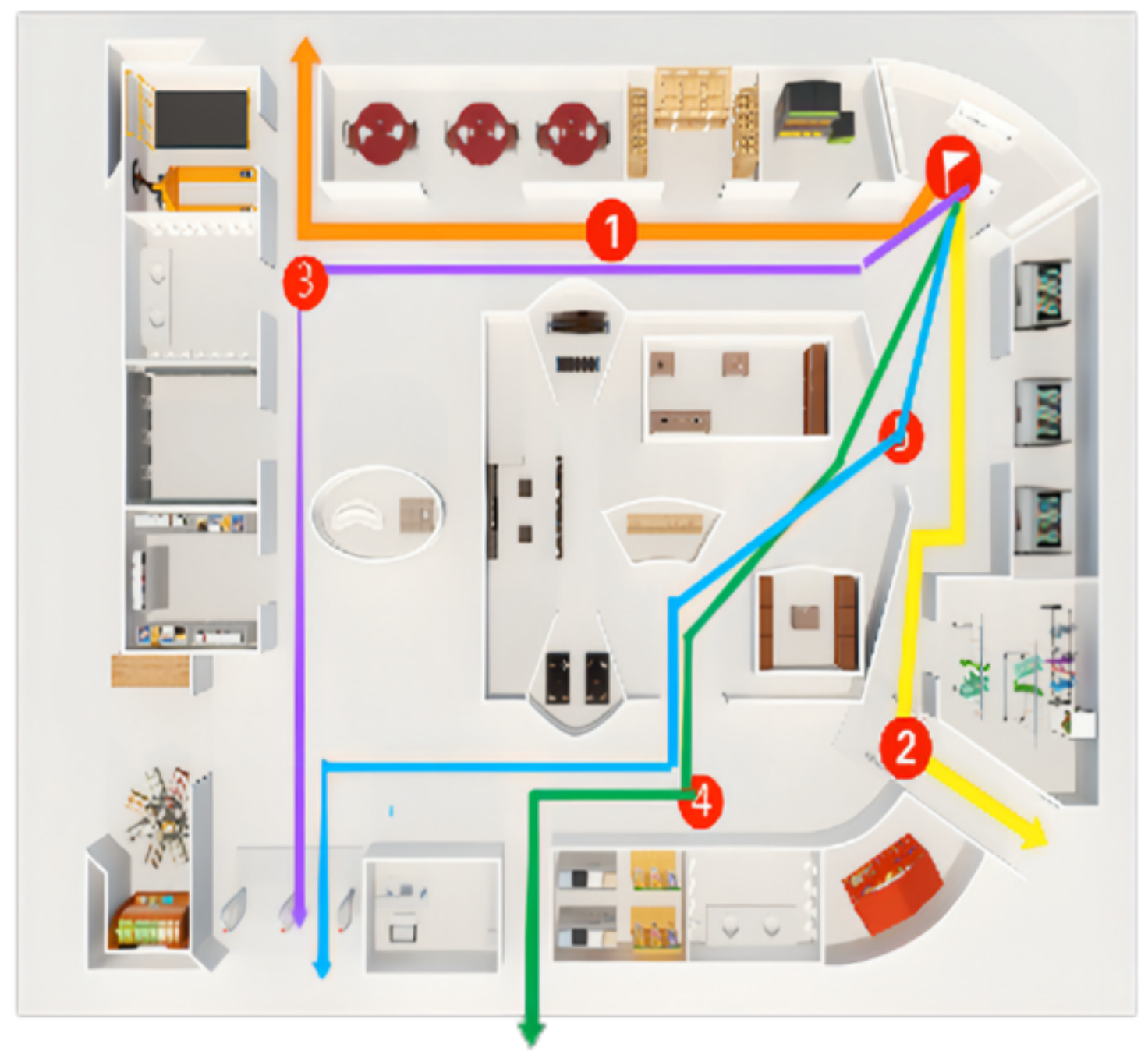

Figure 2

Five evacuation routes 


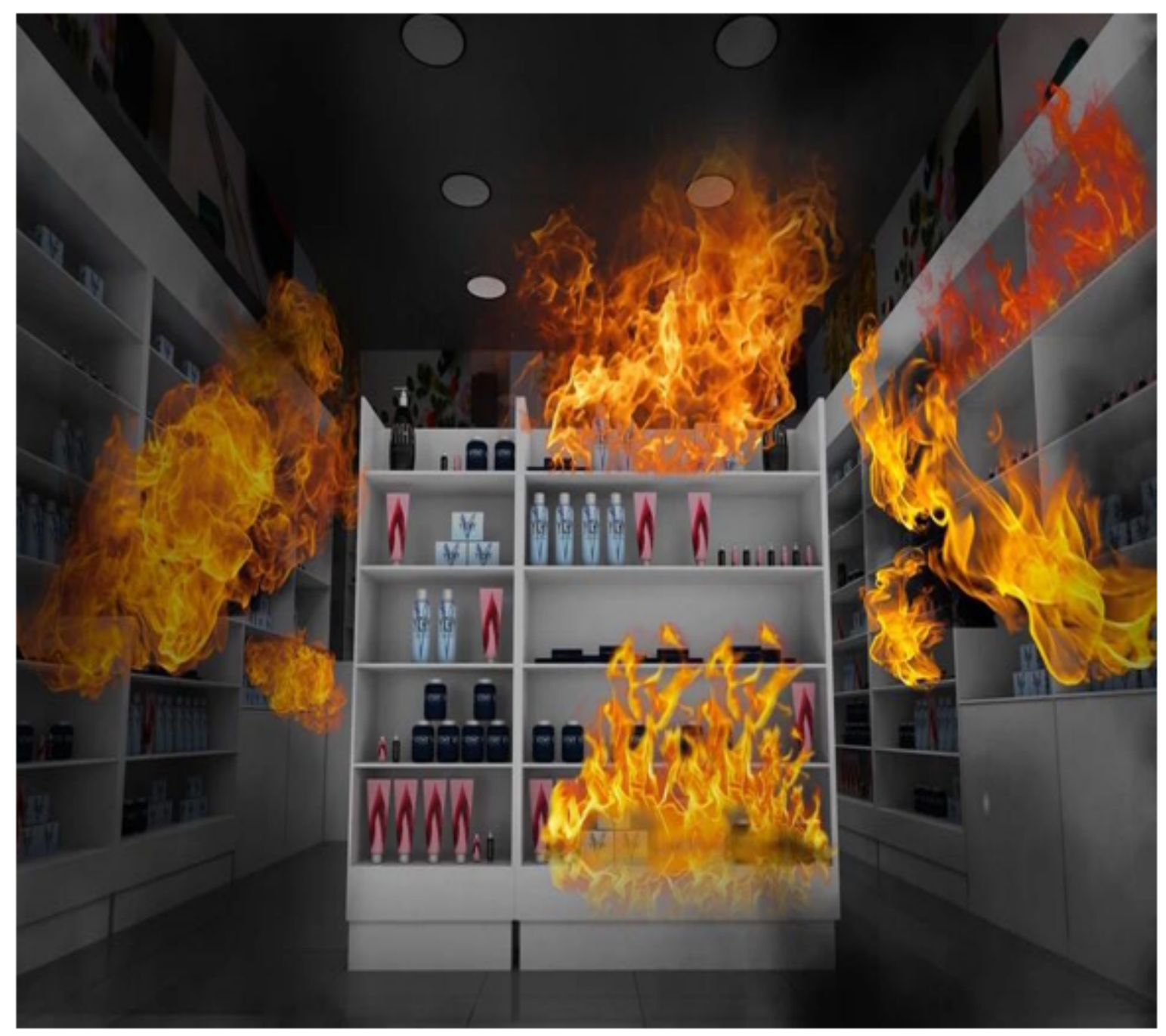

Figure 3

Pictures of fire and smoke

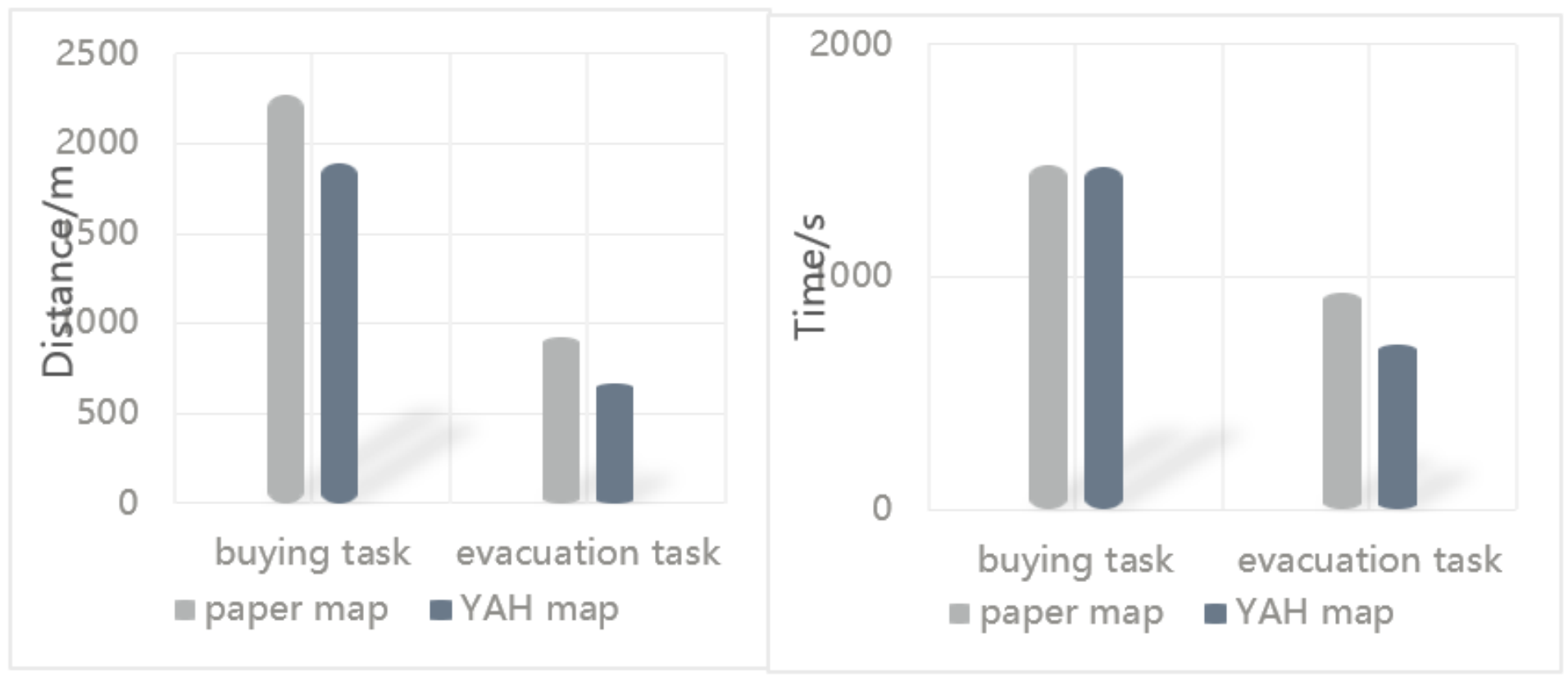


Figure 4

The waking distance and walking time of different spatial cognition methods

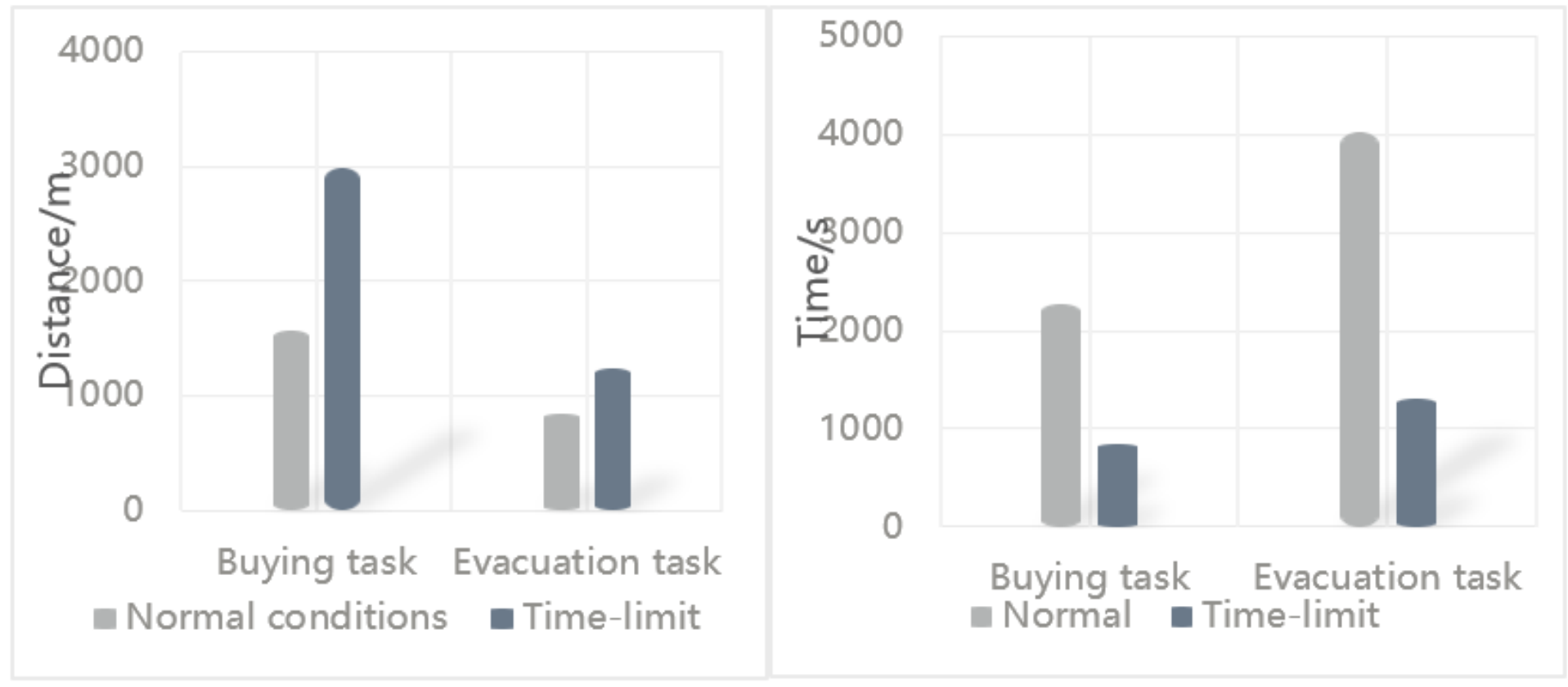

\section{Figure 5}

Walking distance and time of different experimental conditions

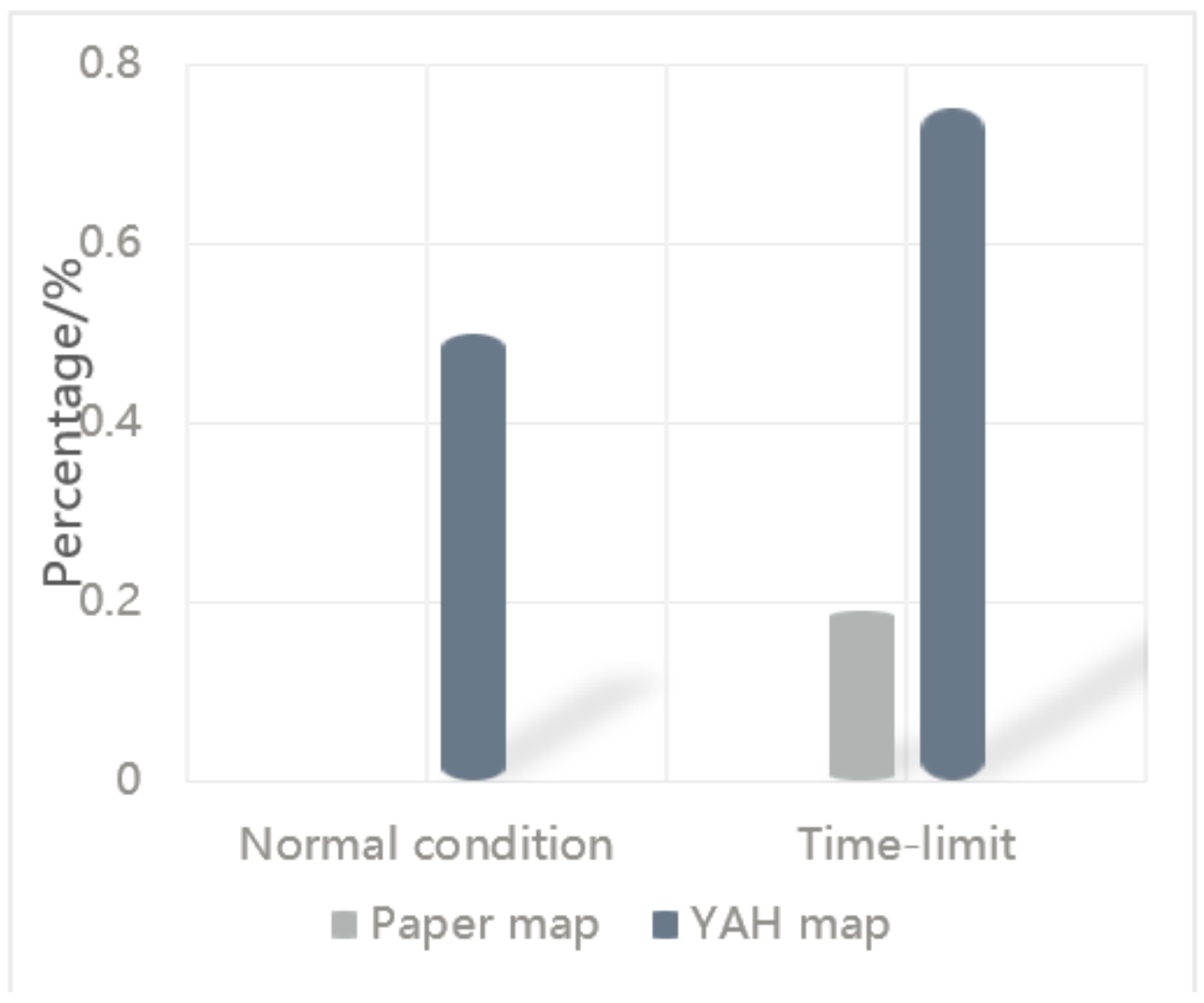

Figure 6 
Percentage of path 2 selection for evacuation under different spatial cognition methods

\section{Supplementary Files}

This is a list of supplementary files associated with this preprint. Click to download.

- supportingmaterial.docx 